\title{
Aerobic and anaerobic microbiology in intra- abdominal infections associated with diverticulitis
}

\author{
ITZHAK BROOK and EDITH H. FRAZIER \\ Department of Infectious Diseases, Naval Hospital, Bethesda, MD, USA
}

\begin{abstract}
The aerobic and anaerobic microbiology of intra-abdominal infections associated with diverticulitis was studied in 110 specimens from the peritoneal cavity after intestinal perforation and in 22 specimens from abdominal abscesses. Anaerobic bacteria only were isolated from $17(15 \%)$ of the peritoneal specimens, aerobic bacteria only from 12 (11\%) and mixed aerobic and anaerobic flora from 81 (74\%). A total of 339 bacterial isolates was detected in peritoneal cultures (3.1 per specimen), comprising 155 aerobes (1.4 per specimen) and 184 anaerobes (1.7 per specimen). Anaerobic bacteria only were isolated in $4(18 \%)$ abscesses, aerobes alone in one $(5 \%)$ and mixed aerobic and anaerobic flora in 17 (77\%). A total of 72 bacterial isolates (3.3 per specimen) was detected in abdominal abscesses -35 aerobes (1.6 per specimen) and 37 aerobes (1.7 per specimen). The predominant aerobic and facultative bacteria in abdominal infections were Escherichia coli and Streptococcus spp. The most frequently isolated anaerobes were Bacteroides spp. (B. fragilis group), Peptostreptococcus, Clostridium and Fusobacterium spp.
\end{abstract}

\section{Introduction}

The microbiology of intra-abdominal infections after perforation of the viscus has been established by numerous studies [1-7]. Polymicrobial aerobic and anaerobic organisms were found to predominate in the majority of patients, with an average number of isolates of approximately five per infection site [1-7]. Generally, the specific micro-organisms involved in these infections are those of the normal flora of the gastrointestinal tract, in which anaerobes reach a concentration of $10^{9-11}$ organisms $/ \mathrm{ml}$ and outnumber aerobes 1000:1 [8].

Previous studies of intra-abdominal infections described the microbiological findings in peritonitis or abscesses that occurred after perforation of the appendix [1], or combined all other causes of perforation of the viscus [2-7]. Although some studies included infections associated with diverticulitis $[6,7]$,

Received 22 Feb. 2000; accepted 10 March 2000. Corresponding author: Dr I. Brook (e-mail: Brook@mx.afrri. usuhs.mil).

The opinions and assertions contained herein are the private ones of the authors and are not to be construed as official or reflecting the views of the US Navy Department or the USA Naval Service at large. none defined the specific findings following this condition.

This retrospective study analysed the aerobic and anaerobic microbiology of intra-abdominal infections (peritonitis and intra-abdominal abscesses) that were associated with diverticulitis in a tertiary care military hospital during a 15-year period.

\section{Patients and methods}

Specimens included in the analysis were obtained from patients who developed their infection as a complication of diverticulitis between June 1978 and June 1993; 132 clinical specimens of peritoneal fluid, and 27 specimens of pus from abdominal abscesses were submitted to the clinical microbiological laboratory at the Navy Medical Center in Bethesda, Maryland. Bacterial growth was present in $113(89 \%)$ peritoneal fluid specimens and 25 (93\%) abscesses. However, the final analyses was based on the 110 patients with peritonitis and 22 with abdominal abscesses whose clinical data were available for analysis. Patients' ages ranged from 42 to 84 years (average 57.2 years), and 69 patients with peritonitis and 18 with abscesses were male.

Antimicrobial agents were given to 79 patients with 
peritonitis and 18 with abscesses before collection of samples. These antimicrobial agents included a penicillin (28 patients), a cephalosporin (41), an aminoglycoside (30), clindamycin (21), metronidazole (8), imipenem (5) and erythromycin (2).

Specimens submitted to the microbiology laboratory were obtained through an open surgical procedure, either by aspiration of the pus into a syringe that was sealed with a rubber stopper after evacuation of the air or by a swab that was transported in an anaerobic transport tube (Port-A-Cul; Becton Dickinson, Sparks, MD, USA). The time between collection of material and inoculation of specimens ranged from $30 \mathrm{~min}$ to $2 \mathrm{~h}$.

Specimens were inoculated on to sheep blood 5\%, chocolate and MacConkey agar plates for aerobes and facultative organisms. The plates were incubated aerobically at $37^{\circ} \mathrm{C}$ (MacConkey) or in air with $\mathrm{CO}_{2}$ $5 \%$ (sheep blood 5\% and chocolate) and examined at 24 and $48 \mathrm{~h}$. For anaerobes, the material was plated on to pre-reduced brucella blood agar enriched with vitamin $\mathrm{K}_{1}$, an anaerobic blood agar plate containing kanamycin and vancomycin, an anaerobic blood agar plate containing phenylethyl alcohol and an enriched thioglycolate broth containing haemin and vitamin $\mathrm{K}_{1}$ [9]. The anaerobic plates and thioglycolate broth were incubated in GasPak jars (Baltimore Biological Laboratories, Baltimore, MD, USA) and examined at 48 and $96 \mathrm{~h}$. Anaerobes were identified by techniques described previously [9]. Aerobic bacteria were identified by conventional methods [10].

Blood was drawn, most often from an antecubital vein, after preparation of the area with povidone/iodine, and it was inoculated at the bedside into two bottles, one supportive of growth of aerobic bacteria and the other supportive of anaerobic bacterial growth.

\section{Results}

\section{Peritoneal cavity}

Anaerobic bacteria alone were present in $17(15 \%)$ of 110 specimens, aerobes alone in $12(11 \%)$ and mixed aerobic and anaerobic flora in $81(74 \%)$. A total of 339 bacterial isolates was obtained from the specimens (3.1 per specimen) (Tables 1 and 2), comprising 155 aerobic or facultative organisms (1.4 per specimen) and 184 anaerobes (1.7 per specimen).

The most frequently isolated aerobic or facultative organisms were Escherichia coli, $\gamma$-haemolytic streptococci, $\alpha$-haemolytic streptococci, group D streptococci, Klebsiella spp. and Pseudomonas aeruginosa. The predominant anaerobes were Bacteroides spp. (B. fragilis group), Peptostreptococcus, Clostridium, Fusobacterium and Prevotella spp., and Porphyromonas asaccharolytica. Polymicrobial infection occurred in $103(94 \%)$ instances. No consistent patterns of bacterial combinations were noted except between the Bacteroides spp. and E. coli in 37 instances.

\section{Abscesses}

Anaerobic bacteria alone were present in 4 (18\%) of 22 specimens, aerobes alone in $1(5 \%)$ and mixed aerobic and anaerobic flora in $17(77 \%)$. In all, there were 72 bacterial isolates (3.3 isolates per specimen) - 37

Table 1. Aerobic and facultative organisms isolated from patients with intraabdominal infections associated with diverticulitis

\begin{tabular}{|c|c|c|}
\hline \multirow[b]{2}{*}{ Organism } & \multicolumn{2}{|c|}{ Number of isolates from } \\
\hline & $\begin{array}{l}\text { Peritoneal fluid } \\
\qquad(\mathrm{n}=110)\end{array}$ & $\begin{array}{c}\text { Intra-abdominal abscess } \\
(\mathrm{n}=22)\end{array}$ \\
\hline \multicolumn{3}{|l|}{ Gram-positive cocci } \\
\hline$\alpha$-Haemolytic streptococci & 12 & 6 \\
\hline$\gamma$-Haemolytic streptococci & 14 & 2 \\
\hline Group D streptococci & 11 & 3 \\
\hline Group $\mathrm{A}, \beta$-haemolytic streptococci & 3 & $\ldots$ \\
\hline Group $\mathrm{C}, \beta$-haemolytic streptococci & 2 & $\ldots$ \\
\hline Group $\mathrm{F}, \beta$-haemolytic streptococcus & 1 & $\ldots$ \\
\hline Staphylococcus epidermidis & 2 & $\ldots$ \\
\hline S. aureus & 1 & 1 \\
\hline \multicolumn{3}{|l|}{ Gram-positive bacilli } \\
\hline Corynebacterium spp. & 2 & $\ldots$ \\
\hline \multicolumn{3}{|l|}{ Gram-negative bacilli } \\
\hline Haemophilus spp. & 1 & $\ldots$ \\
\hline Eikenella corrodens & 2 & $\ldots$ \\
\hline Pseudomonas aeruginosa & 7 & 1 \\
\hline Escherichia coli & 72 & 15 \\
\hline Klebsiella pneumoniae & 8 & 3 \\
\hline K. oxytoca & 4 & $\ldots$ \\
\hline Enterobacter spp. & 3 & $\ldots$ \\
\hline Serratia marcescens & 2 & 1 \\
\hline Proteus spp. & 3 & 1 \\
\hline Enterobacteriaceae (other) & 5 & 2 \\
\hline Total number of aerobic and facultative isolates & 155 & 35 \\
\hline
\end{tabular}


Table 2. Anaerobic organisms isolated from patients with intra-abdominal infections associated with diverticulitis

\begin{tabular}{|c|c|c|}
\hline \multirow[b]{2}{*}{ Organism } & \multicolumn{2}{|c|}{ Number of isolates } \\
\hline & $\begin{array}{l}\text { Peritoneal fluid } \\
\quad(\mathrm{n}=110)\end{array}$ & $\begin{array}{c}\text { Intra-abdominal abscess } \\
(\mathrm{n}=22)\end{array}$ \\
\hline \multicolumn{3}{|l|}{ Gram-positive cocci } \\
\hline Peptostreptococcus spp. & 8 & 2 \\
\hline Pstr. magnus & 3 & 2 \\
\hline Pstr. asaccharolyticus & 3 & 1 \\
\hline Pstr. prevotii & 2 & $\ldots$ \\
\hline Pstr. micros & 3 & $\ldots$ \\
\hline Pstr. anaerobius & 2 & 1 \\
\hline Pstr. morbilorum & 2 & $\ldots$ \\
\hline Streptococcus intermedius & 1 & $\ldots$ \\
\hline Microaerophilic streptococci & 1 & $\ldots$ \\
\hline \multicolumn{3}{|l|}{ Gram-negative cocci } \\
\hline Veillonella parvulla & 2 & 1 \\
\hline V. alcalesence & 1 & $\ldots$ \\
\hline \multicolumn{3}{|l|}{ Gram-positive bacilli } \\
\hline Bifidobacterium spp. & 1 & $\ldots$ \\
\hline Eubacterium spp. & 4 & $\ldots$ \\
\hline Eu. lentum & 7 & 1 \\
\hline Lactobacillus spp. & 2 & $\ldots$ \\
\hline Propionibacterium acnes & 6 & $\ldots$ \\
\hline Clostridium spp. & 12 & 3 \\
\hline C. perfringens & 10 & 2 \\
\hline C. ramosum & 4 & $\ldots$ \\
\hline C. butyricum & 1 & $\ldots$ \\
\hline C. clostridiiforme & 2 & $\ldots$ \\
\hline C. septicum & 2 & $\ldots$ \\
\hline \multicolumn{3}{|l|}{ Gram-negative bacilli } \\
\hline Fusobacterium spp. & 7 & 1 \\
\hline F. varium & 1 & $\ldots$ \\
\hline F. necrophorum & 2 & $\ldots$ \\
\hline F. nucleatum & 3 & $\ldots$ \\
\hline Bacteroides spp. & 10 & 1 \\
\hline B. fragilis & 44 & 14 \\
\hline B. ovatus & 7 & 2 \\
\hline B. vulgatus & 7 & ... \\
\hline B. distasonis & 6 & 1 \\
\hline B. thetaiotaomicron & 11 & 2 \\
\hline B. uniformis & 1 & $\ldots$ \\
\hline Porphyromonas asaccharolytica & 2 & 1 \\
\hline Prevotella intermedia & 1 & $\ldots$ \\
\hline Pr. melaninogenica & 2 & 2 \\
\hline Pr. bivia & 1 & \\
\hline Total number of anaerobic isolates & 184 & 37 \\
\hline
\end{tabular}

anaerobes (1.7 per specimen) and 35 aerobic or facultative anaerobes (1.6 per specimen) (Tables 1 and 2). The predominant aerobic and facultative organisms were E. coli and Streptococcus spp. The most frequently isolated anaerobes were Bacteroides spp., Peptostreptococcus and Clostridium spp. Polymicrobial flora were recovered in $19(86 \%)$ patients. No consistent patterns of bacterial combinations were noted except between the Bacteroides spp. and E. coli in 11 instances.

Sixteen organisms identical to that isolated from the peritoneal cavity and seven similar to those found in the abscesses were also isolated from blood cultures in $13(17 \%)$ of the 76 cases of peritonitis and $5(33 \%)$ of the 15 cases of abscesses in which blood cultures were performed. These organisms were E. coli (7), Bacteroides spp. (5), Peptostreptococcus spp. (4), Klebsiella pneumoniae (3), Fusobacterium spp. (2) and Clostridium spp. (2).

\section{Discussion}

This study demonstrates the presence of mixed aerobic and anaerobic flora in secondary peritonitis and intraabdominal abscesses associated with diverticulitis. These data conform with those of previous studies of intra-abdominal infection due to ruptured appendix [1] and other causes of rupture of viscus [2-7], in which B. fragilis, E. coli and Peptostreptococcus spp. were the predominant pathogens. The findings of similar micro-organisms in intra-abdominal infections associated with diverticulitis as in infections due to other causes of rupture of the viscus is not surprising, as the origin of all these infections is the gastrointestinal flora.

The importance of the aerobic and anaerobic components of these infections has been demonstrated in experimental studies of animals [11]. B. fragilis, the most prevalent among the anaerobes isolated, has 
several virulence factors. These include resistance to $\beta$ lactam antibiotics through production of the enzyme $\beta$ lactamase [12], elaboration of other enzymes and byproducts and possession of a capsule that inhibits phagocytosis [13].

The relationship between the aerobic and anaerobic bacteria in these infections has been shown to be synergic [11]. Several hypotheses have been proposed to explain such microbial synergy. It may be a result of mutual protection from phagocytosis and intracellar killing [13], production of essential growth factors [14] or lowering of oxidation-reduction potentials in host tissues [15].

This study underscores the importance of obtaining specimens for the investigation of both aerobic and anaerobic bacteria from abdominal infections associated with diverticulitis. Management of mixed aerobic and anaerobic infections requires, in addition to surgical correction and drainage of pus, the administration of antimicrobial agents effective against both aerobic and anaerobic bacterial components of the infection [16-18]. When such therapy is not given, the infection may persist and a complication such as an abscess may occur.

The environment of an abscess is detrimental to many antimicrobial agents. The abscess capsule, the low $\mathrm{pH}$ and the presence of binding proteins or inactivating enzymes such as $\beta$-lactamase may impair the activity of many agents [19]. Because of these limitations, drainage is still the therapy of choice when abscesses have already developed.

We acknowledge the efforts of the staffs of the clinical microbiology laboratories and the clinical wards at the Navy Hospital in Bethesda and the secretarial assistance of Sarah Blaisdell.

\section{References}

1. Gorbach SL, Thadepalli H, Norsen J. Anaerobic microorganisms in intraabdominal infections. In: Balows A, DeHann RM,
Dowell VR, Guze LB. Anaerobic bacteria: role in disease. Springfield, IL, Charles C. Thomas Co. 1974: 399-407.

2. Greenberg RN, Cayavec P, Danko LS et al. Comparison of cefoperazone plus sulbactam with clindamycin plue gentamicin as treatment for intra-abdominal infections. $J$ Antimicrob Chemother 1994; 34: 391-401.

3. Christou NV, Turgeon P, Wassef R et al. Management of intraabdominal infections. The case for intraoperative cultures and comprehensive broad-spectrum antibiotic coverage. Arch Surg 1996; 131: 1193-1201.

4. Brismar B, Åkerland J-E, Sjöstedt S et al. Biapenem versus imipenem/cilastatin in the treatment of complicated intraabdominal infections: report from a Swedish Study Group. Scand J Infect Dis 1996; 28: 507-512.

5. Angerås MH, Darle N, Hamnström $\mathrm{K}$ et al. A comparison of imipenem/cilastatin with the combinatin of cefiroxime and metronidazole in the treatment of intra-abdominal infections. Scand J Infect Dis 1996; 28: 513-518.

6. Mosdell DM, Morris DM, Voltura A et al. Antibiotic treatment for surgical peritonitis. Ann Surg 1991; 241: 543-549.

7. Brook I, Frazier EH. Aerobic and anaerobic microbiology of retroperitoneal abscesses. Clin Infect Dis 1998; 26: 938-941.

8. Gorbach SL. Intestinal microflora. Gastroenterology 1971; 60: 1110-1129.

9. Sutter VL, Citron DM, Edelstein MAC, Finegold SM. Wadsworth anaerobic bacteriology manual. 4th edn. Belmont, CA, Star Publishing. 1985.

10. Lennette EH, Balows A, Hausler WJ, Shadomy HJ. Manual of clinical microbiology, 4th edn. Washington, DC, American Society for Microbiology. 1985.

11. Brook I, Hunter V, Walker RI. Synergistic effect of Bacteroides, Clostridium, Fusobacterium, anaerobic cocci, and aerobic bacteria on mortality and induction of subcutaneous abscesses in mice. $J$ Infect Dis 1984; 149: 924-928.

12. Brook I, Calhoun L, Yocum P. Beta-lactamase-producing isolates of Bacteroides species from children. Antimicrob Agents Chemother 1980; 18: 164-166.

13. Tofte RW, Peterson PK, Schemling D, Bracke J, Kim Y, Quie PG. Opsonization of four Bacteroides species: role of the classical complement pathway and immunoglobulin. Infect Immun 1980; 27: 784-792.

14. Lev M, Krudell KC, Milford AF. Succinate as a growth factor for Bacteroides melaninogenicus. J Bacteriol 1971; 108: $175-178$.

15. Mergenhagen SE, Thonard JD, Scherp HW. Studies on synergistic infections. 1. Experimental infections with anaerobic streptococci. J Infect Dis 1958; 103: 33-44.

16. Thadepalli H, Gorbach SL, Broido PW, Norsen J, Nghus L. Abdominal trauma, anaerobes, and antibiotics. Surg Gynecol Obstet 1973; 137: 270-176.

17. Finegold SM. Anaerobic bacteria in human disease. New York, Acadmeic Press. 1977.

18. Bohnen JM, Solomkin JS, Dellinger EP, Bjornson HS, Page CP. Guidelines for clinical care: anti-infective agents for intraabdominal infection. A Surgical Infection Society policy statement. Arch Surch 1992; 127: 83-89.

19. Verklin RM, Mandell GL. Alteration of effectiveness of antibiotics by anaerobiosis. J Lab Clin Med 1977; 89: 65-71. 